\title{
Performance Testing of Diesel Engine using Cardanol-Kerosene oil blend
}

\author{
Ravindra ${ }^{1 *}$, Aruna $\mathrm{M}^{1}$ and Vardhan Harsha ${ }^{1}$ \\ ${ }^{1}$ Department of Mining Engineering, National Institute of Technology Karnataka, Surathkal, 575025, \\ India
}

\begin{abstract}
Awareness of environmental pollution and fossil fuel depletion has necessitated the use of biofuels in engines which have a relatively cleaner emissions. Cardanol is a biofuel, abundantly available in India, which is a by-product of cashew processing industries. In this study performance of raw Cardanol blended with kerosene has been tested in diesel engine. Volumetric blend BK30 (30\% kerosene and 70\% Cardanol) has been used for the test. The properties like flash point, viscosity and calorific value of the blend have been determined. The test was carried out in four stroke diesel engine connected with an eddy current dynamometer. Performance of the engine has been analysed by finding the brake specific fuel consumption (BSFC) and brake thermal efficiency (BTE). The results showed that the brake thermal efficiency of the blend is $29.87 \%$, with less $\mathrm{CO}$ and smoke emission compared to diesel. The results were also compared with the performance of Cardanol diesel blend and Cardanol camphor oil blend, which were already tested in diesel engines by other researchers. Earlier research work reveals that the blend of 30\% camphor oil and $70 \%$ Cardanol performs very closer to diesel fuel with a thermal efficiency of $29.1 \%$. Similarly, higher brake thermal efficiency was obtained for $20 \%$ Cardanol and $80 \%$ diesel blend.
\end{abstract}

Keywords: Biofuel; Cardanol; Kerosene; Emission; Alternative fuel

\section{Introduction}

The reserves of fossil fuels were depleting due to their increased usage. The inventors in the field of fuels have to think about an alternative to fossil fuel, which is renewable in nature and green to environment. Biofuels were one such source of fuel originated from plants and animals [1]. The oils extracted from seeds such as coconuts, cotton seed, soya bean, sunflower, jatropha, peanuts, mustard seed, linseed, palm and cashew nuts are converted to biodiesel and tested as a substitute fuel for CI engines [2, 3].

The Cardanol is a by-product of cashew industry, extracted from CNSL. It is abundantly available at low cost in India. Cardanol has been tested in diesel engine as a fuel by many researchers. Cardanol was blended with diesel and its performance and emissions were studied in a double cylinder CI engine. One such study reported that up to $20 \%$ Cardanol

\footnotetext{
* Corresponding author: ravindra@nitte.edu.in
} 
blending with diesel the emissions were lower with improved efficiency [4]. To reduce the viscosity of Cardanol it was preheated up to $80^{\circ} \mathrm{C}$ before blending with diesel. The diesel engines operated with preheated Cardanol diesel blend reported 20\% higher BTE than unheated oil [5]. Cardanol was mixed with $10 \%$ methanol as an additive and blended with diesel. The B20M10 blend (20\% Cardanol, 70\% diesel and 10\% methanol) showed lower emissions and improved BTE in CI engines [6]. Diesel engines operated with B20M10 blend with extra intake oxygen also reported improvement in BTE with less emissions [7]. In another study Cardanol was blended with camphor oil to reduce its viscosity and the blend has been tested in CI engine [8]. The performance of CMPRO30 (30\% camphor oil and $70 \%$ Cardanol) blend was very close to diesel fuel. Some of the researchers have blended the biodiesel with kerosene and tested the possibility of usage of the blend as a fuel in diesel engines. They reported improvement in performance with lower emissions [9, 10]. In the present study Cardanol has been blended with kerosene to reduce the viscosity and the blend has been tested in diesel engine. The results were compared with the performance of diesel Cardanol blend and camphor oil Cardanol blend.

\section{Materials and Methods}

The test fuel Cardanol has been purchased from a local cashew industry. The kerosene and diesel has been purchased from local market. The test blend BK30 (30\% kerosene and 70\% cardanol) was prepared by mixing 30\% kerosene and $70 \%$ Cardanol on volume basis. The properties, like flash point, calorific value and kinematic viscosity of the blend and diesel fuel has been determined as per ASTM standards. The kinematic viscosity was determined as per ASTM standard D445 using Cannon-Fenske Viscometer. The flash point was determined using Pensky-Martens closed cup apparatus as per ASTM Standard D93. The calorific value of the fuels were found using bomb calorimeter as per ASTM Standard D240. The results of all these tests were tabulated in Table 1.

Table 1. Properties of diesel and BK30 blend

\begin{tabular}{|l|l|l|l|}
\hline Properties & ASTM code & Diesel & BK30 \\
\hline Kinematic viscosity @ $40^{\circ} \mathrm{C}$ (in cSt) & D445 & 3.17 & 5.9 \\
\hline Flash point(in $\left.{ }^{\circ} \mathrm{C}\right)$ & D93 & 51 & 65 \\
\hline Calorific value (in $\mathrm{kJ} / \mathrm{kg})$ & D240 & 43580 & 41331 \\
\hline
\end{tabular}

The experiments have been conducted in a four stroke water cooled CI engine running at $1500 \mathrm{rpm}$ (Fig. 1).The engine technical specifications were given in Table 2. The load on the engine was applied by a water cooled eddy current dynamometer, which was directly connected to the engine. Thermocouples were mounted on the exhaust gas calorimeter for temperature measurement. A burette was fitted in the fuel line for the measurement of fuel consumption. The exhaust emissions was measured using exhaust gas analyser (Netel exhaust gas analyser, Model: NPM-MGA-1) and the smoke opacity was measured by using smoke meter (Netel smoke meter model, NPM-SM-111B).

The initial settings of the engine were checked as per manufacturer specification. The water flow rate through engine and calorimeter were adjusted to 250 litres/hour and 100 litres/hour, respectively. Diesel and BK30 blend were filled separately in the dual fuel tank. The air lock on the fuel line, if any, was cleared by loosening the set screw at the fuel pump. Start the engine with diesel fuel by cranking and warmed up for 15 minutes. Load was applied and fuel consumption rate was measured. The exhaust gas temperature, 
Exhaust emissions and smoke values were noted. The trail was repeated three times to get repeated values and average value was considered. Then the engine was operated with the BK30 blend by changing the position of the fuel tank valve and the same procedure was repeated. The brake specific fuel consumption and BTE can be calculated using the equations given below.

$\mathrm{BSFC}=$ mass flow rate of fuel / Brake power

$\mathrm{BTE}=1 / \mathrm{BSFC} \mathrm{x}$ lower calorific value

Table 2. Engine specifications

\begin{tabular}{|l|l|}
\hline Number of cylinders & 1 \\
\hline Number of strokes & 4 \\
\hline Power & $3.5 \mathrm{~kW}$ \\
\hline Bore and stroke & $87.5 \mathrm{~mm} \times 110 \mathrm{~mm}$ \\
\hline Rated speed & $1500 \mathrm{RPM}$ \\
\hline Compression ratio & 12 to18:1(18:1) \\
\hline Dynamometer arm length & $184 \mathrm{~mm}$ \\
\hline
\end{tabular}

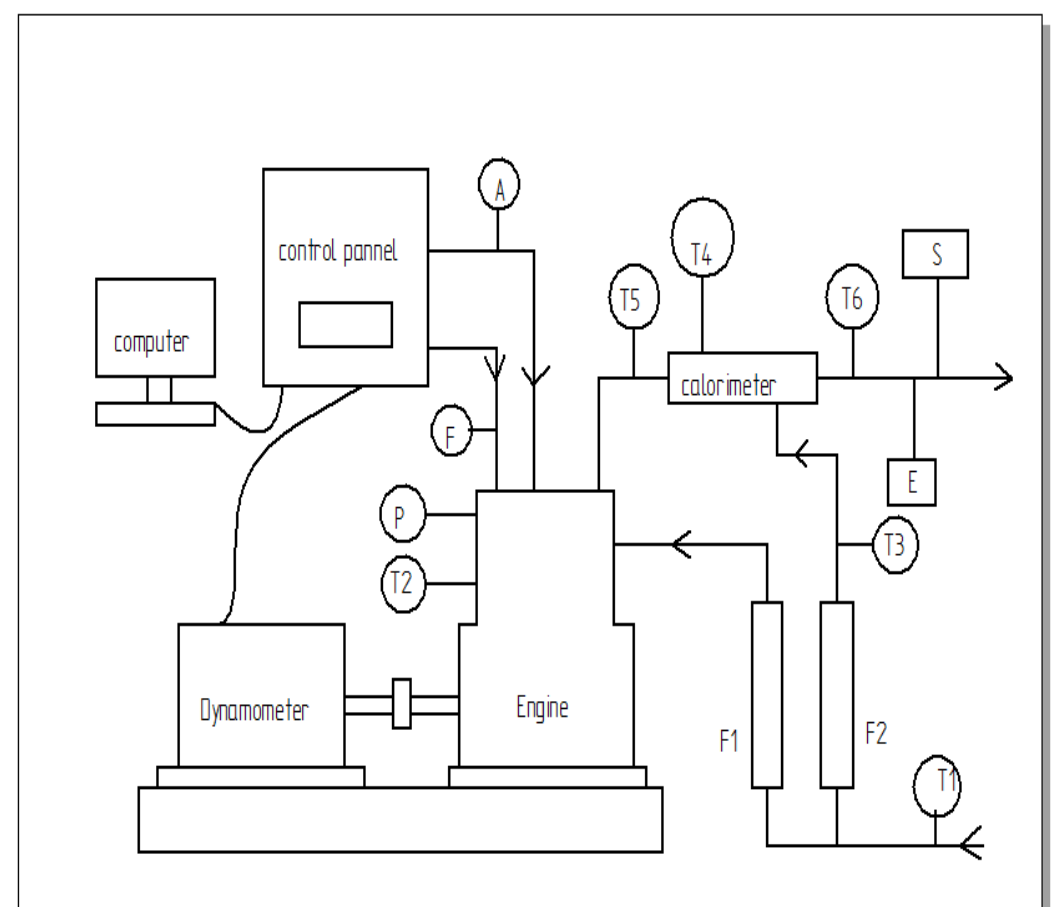

Fig. 1. Experimental Set up

P: Pressure sensor

A: Air flow rate measurement

F: Fuel flow rate measurement

F1: Water flow rate through engine

F2: Water flow rate through calorimeter 
S: $\quad$ Smoke meter

E: Exhaust gas analyser

T1 and T2: $\quad$ Engine inlet and outlet jacket water temperature

T3 and T4: Calorimeter inlet and outlet water temperature

T5 and T6: Exhaust gas temperature at inlet and outlet of calorimeter

\section{Results and Discussions}

The raw Cardanol was blended with 30\% kerosene and the blend was tested in diesel engine to find the feasibility of using it as a fuel. Fig. 2 shows the variation of BTE for BK30 blend and diesel at various loading conditions. At peak load the BTE of BK30 blend was $29.87 \%$ and for diesel it was $30.36 \%$. The engine was operating smoothly with the blend at all the loads similar to diesel fuel. By blending kerosene with Cardanol the combustion was fast because of vigorous burning of kerosene, so the BTE was only $1.6 \%$ less than diesel fuel. At lower load, due to low combustion chamber temperature the combustion was slow. More BK30 fuel was injected compared to diesel (higher BSFC) at lower loads. So more kerosene particles available which are more volatile than diesel. Due to higher volatility of kerosene molecules the surrounding biofuel molecules will burn fast. So at lower load good combustion compared to diesel fuel.

BSFC variations with load is shown in Fig. 3. For BK30 blend a higher BSFC was recorded than diesel fuel, which is due to poor calorific value. The BSFC of the blend was $6.8 \%$ higher than diesel fuel. A higher BSFC for biodiesel blends were already reported [11].

Exhaust gas temperature variations has been represented in Fig. 4. At peak load for BK30 blend EGT was lower than diesel fuel, which shows the fast combustion of the kerosene Cardanol blend. At lower loads due to lower temperature, the combustion of biofuel extended for longer duration which leads to higher exhaust gas temperature.

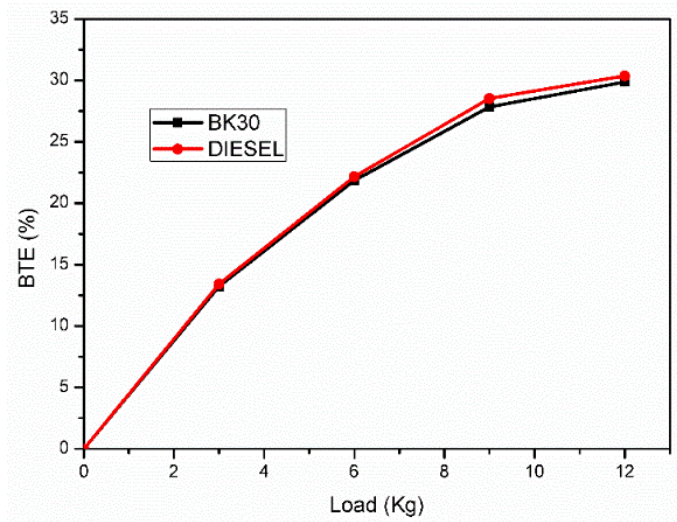

Fig. 2. BTE vs load

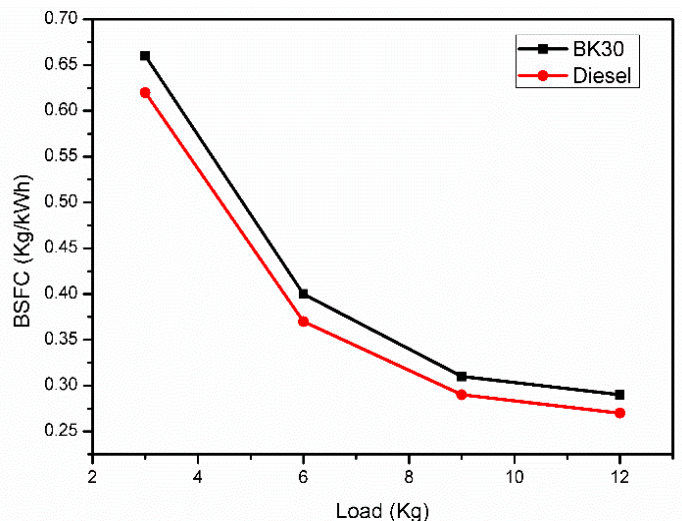

Fig. 3. BSFC vs load 


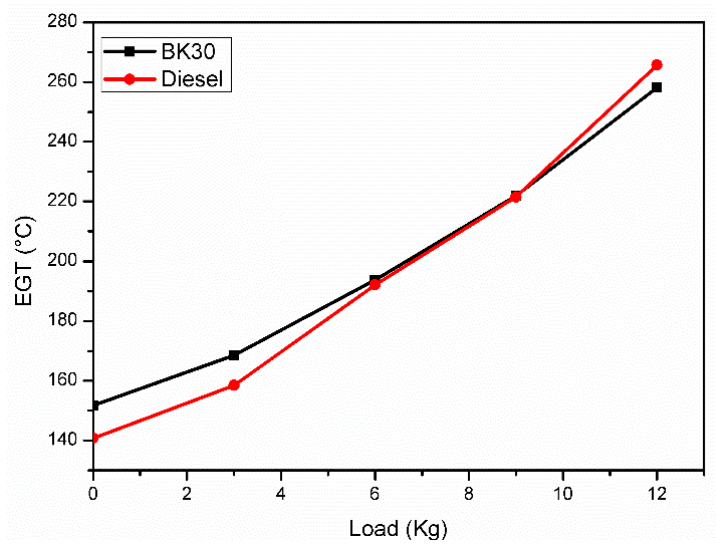

Fig. 4. Exhaust gas temperature vs load

The emission of $\mathrm{CO}$ was due to incomplete combustion. The $\mathrm{CO}$ emission for various loading condition has been presented in Fig. 5. From the figure it was observed that for the Cardanol kerosene blend $\mathrm{CO}$ emission reducing with increase in the load and for diesel fuel it was increasing. Similar observations were recorded by other investigators on diesel fuel $[5,12$, and 13].

The emissions of smoke for different loading conditions was shown in Fig. 6. As shown in Fig. 6 when the load on the engine was increasing the smoke emission was also increasing [14]. At lower loads the Cardanol kerosene blend emits more smoke than diesel fuel. But the smoke was lower for the blend at peak load compared to diesel. At lower loads due to lower temperature the poor combustion of some of the biofuel particles leads to higher smoke emission.

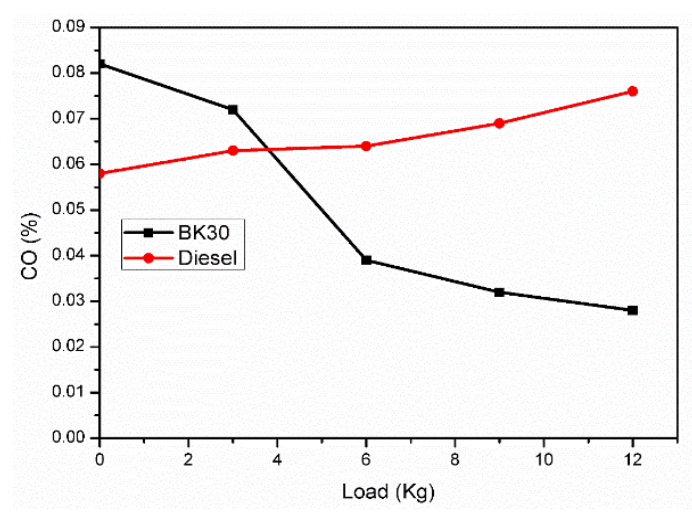

Fig. 5. CO vs load

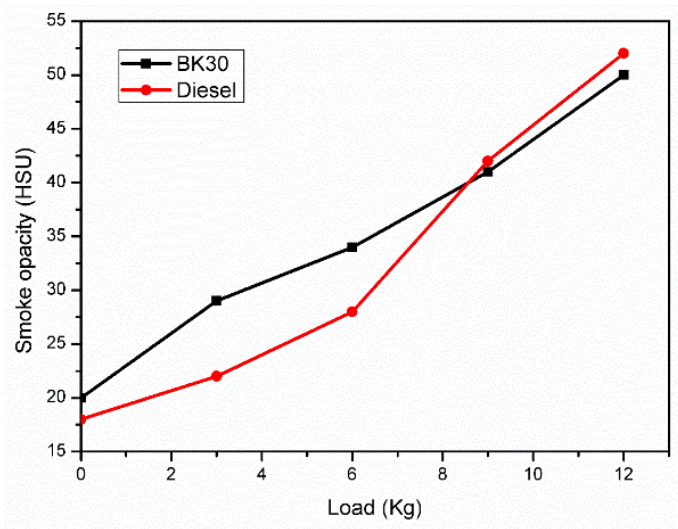

Fig. 6. Smoke vs load

Cardanol has been already used as diesel engine fuel in different ways by many researchers.

Table 3 gives comparison of performance of these kinds of blends. 
Table 3. Comparison of different blends of Cardanol

\begin{tabular}{|l|l|l|l|}
\hline Particulars & $\begin{array}{l}\text { Cardanol Kerosene } \\
\text { blend } \\
(\mathrm{BK} 30)\end{array}$ & $\begin{array}{l}\text { Cardanol camphor oil } \\
\text { blend }[8] \\
\text { (CMPRO30) }\end{array}$ & $\begin{array}{l}\text { Cardanol diesel blend } \\
{[14]} \\
(20 \mathrm{CNSO})\end{array}$ \\
\hline BTE & $29.87 \%$ & $29.1 \%$ & $\sim 28 \%$ \\
\hline EGT & $258^{\circ} \mathrm{C}(531 \mathrm{~K})$ & $686 \mathrm{~K}$ & $224^{\circ} \mathrm{C}(497 \mathrm{~K})$ \\
\hline CO emission & $0.028 \%$ & $0.3 \%$ & $0.62 \%$ \\
\hline Smoke emission & $50 \mathrm{HSU}$ & $3.91 \mathrm{BSU}$ & $\sim 32 \mathrm{BSU}$ \\
\hline
\end{tabular}

From Table 3 it can be observed that brake thermal efficiency of Cardanol kerosene blend and Cardanol camphor oil blend were higher than Cardanol diesel blend with lower emissions of smoke and CO.

\section{Conclusions}

The Cardanol can be blended with kerosene and the blend can be a fuel for CI engine. The performance of BK30 blend is very nearer to diesel fuel with respect to BTE and BSFC. Emissions of smoke and CO with BK30 blend were lower than diesel at peak load. Therefore Cardanol kerosene blend can be replaced for diesel without much modifications in the engine with minimum pollution.

\section{Nomenclature}

$\begin{array}{ll}\text { BTE } & \text { Brake thermal efficiency } \\ \text { CO } & \text { Carbon monoxide } \\ \text { BSFC } & \text { Brake specific fuel consumption } \\ \text { CI } & \text { Compression ignition } \\ \text { EGT } & \text { Exhaust gas temperature } \\ \text { CNSL } & \text { Cashew nut shell liquid }\end{array}$

\section{References}

1. R. Behcet, R.Yumrutas, H. Oktay, Energy, 71, 645-655 (2014)

2. G. Sakthivel, G. Nagarajan, M. Ilangkumaran, A. B. Gaikwad, Fuel, 132, 116-124 (2014)

3. A. Sanjid, H. H. Masjuki, M. A. Kalam, S. M. A. Rahman, M. J. Abedin, S. M. Palash, Journal of Cleaner Production, 65, 295-303 (2014)

4. D. N. Mallikappa, R. P. Reddy, Ch. S. N. Murthy, Renewable Energy, 38, 150-154 (2012)

5. S. Vedharaj, R. Vallinayagam, W. M. Yang, S.K. Chou, K. J. E. Chua, P. S. Lee, International Journal of Green Energy, 12, 359-367(2015)

6. C. Jagadish, B. Patil, P. Mohanan, International Journal of Engineering Research and Technology, 1, 9, 1-6 (2012)

7. P. Dinesha, P. Mohanan, Distributed Generation and Alternative Energy Journal, 30, 1, 6-14 (2015)

8. G. Kasiraman, B. Nagalingam, M. Balakrishnan, Energy, 47, 116-124, (2012) 
9. M. M. Roy, W. Wang, M. Alawi, Energy Conversion and Management, 84, 164-173 (2014)

10. H. Aydin, H. Bayindir, C. Ilkilic, Energy Sources, Part A: Recovery, Utilization and Environmental Effects, 33, 130-137 (2011)

11. S. Godiganur, Ch. S. Murthy, R. P. Reddy, Renewable Energy, 35, 355-359 (2010)

12. J. Devaraj, Y. Robinson, P. Ganapathi, Energy, 85, 304-309 (2015)

13. N. K. Natesan, Energy Sources, Part A: Recovery, Utilization and Environmental Effects, 35, 1648-1656 (2013)

14. S. Santhanakrishnan, B. K. M. Ramani, International journal of Ambient Energy, 38, 1, 104-107 (2017) 